\title{
ORIGIN OF SPURIOUS ULTRASONIC ECHOES IN STAINLESS STEEL PIPING \\ WITH WELD OVERLAY*
}

CONF-860856--13

by

DE87 007009

David S. Kupperman

Materials and Components Technology Division

ARGONNE NATIONAL LABORATORY

Argonne, Illinois 60439

August 1986

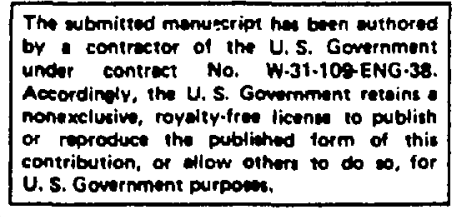

\section{DISCLAIMER}

This report was prepared as an account of work sponsored by an agency of the United States Government. Neither the United States Government nor any agency thereof, nor any of their employees, makes any warranty, express or implied, or assumes any legal liability or responsibility for the accuracy, completeness, or usefulness of any information, apparatus, product, or process disclosed, or represents that its use would not infringe privately owned rights. Reference herein to any specific commercial product, process, or service by trade name, trademark, manufacturer, or otherwise does not necessarily constitute or imply its endorsement, recommendation, or favoring by the United States Government or any agency thereof. The views and opinions of authors expressed herein do not necessarily state or reflect those of the United States Government or any agency thereof.

Paper to be published in the Proceedings of the Review of Progress in Quantitative NDE, held in La Jolla, CA, August 3-8, 1986, sponsored by the Center for NDE at Iowa State University and Ames Laboratory. *Work supported by the U.S. Nuclear Regulatory Commission, Office of
Nuclear Regulatory Research. 
ORIGIN OF SPURIOUS ULTRASONIC ECHOES IN STAINLESS STEEL PIPING

WITH WELD OVERLAY*

\author{
Dav1d S. Kupperman \\ Mater1als and Components Technology Division \\ Argonne National Laboratory \\ Argonne, IL 60439
}

\title{
INTRODUCTION
}

The initlation and growth of intergranular stress-corrosion cracking (IGSCC) in the heat affected zone (HAZ) of stainless steel reactor piping welds has been a subject of concern to electric utilities for over ten years. This type of crack can be detected with ultrasonic shear waves during normal maintenance periods with a reliability of up to $80 \%$ [1]. Often after an inspection indicating cracks, a utility has been allowed to administer a temporary fix to a pipe which is suspected of being cracked. This fix is a weld metal overlay. The repaired pipes of ten have to be inspected after the overlay has been put on the pipe. The overlay with a complex, elastically anisotropic microstructure, considerably reduces the reliability of the ultrasonic inspection. This paper addresses the problems arising because of the overlay.

\section{WORKSHOP ON NDE OF PIPES WITH WELD OVERLAYS}

An NDE workshop on inspection of 12-in. Schedule 80 pipe-to-elbow weldments with weld overlays, from the Georgia Power Co. Hatch-2 reactor, was held at ANL in May 1984 [2]. Because of the positive response to this workshop, a second one was held at ANL in January 1985. The ten participants included personnel from KWU (West Germany), Commonwealth Edison, Battelle Pacific Northwest Laboratory (PNL), Southwest Research Institute, and ANL. Two pipe-to-endcap weldments with weld overlays, also from Hatch, were studied in the second workshop. Figure 1 shows the dimensions and configurations of these weldments. The endcap is intact on weldment 22BM, a photograph of which is shown in Fig. 2. The inner surfaces of the weldments have been ground in some areas so that they contain a mixture of smooth areas and areas where the weld root is clearly evident. The weld overlay has a relatively smooth surface texture.

*Work supported by the U. S. Nuclear Regulatory Commission, Office of Nuclear Regulatory Research. 

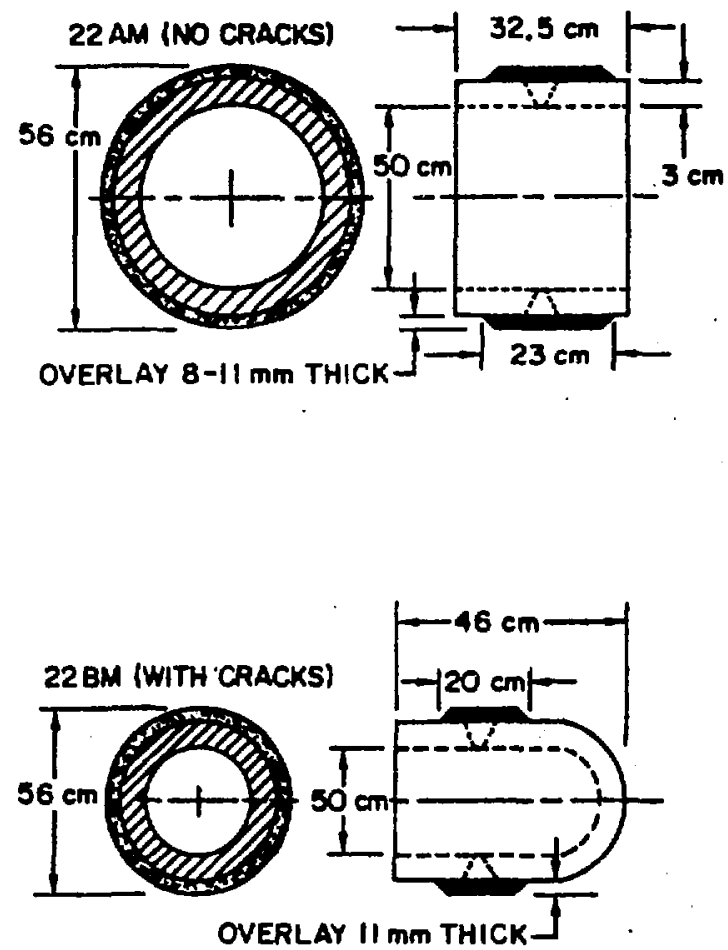

Fig. 1. Schematics of the Two Pipe-to-Endcap Weldments Used in the 1985 NDE Workshop.

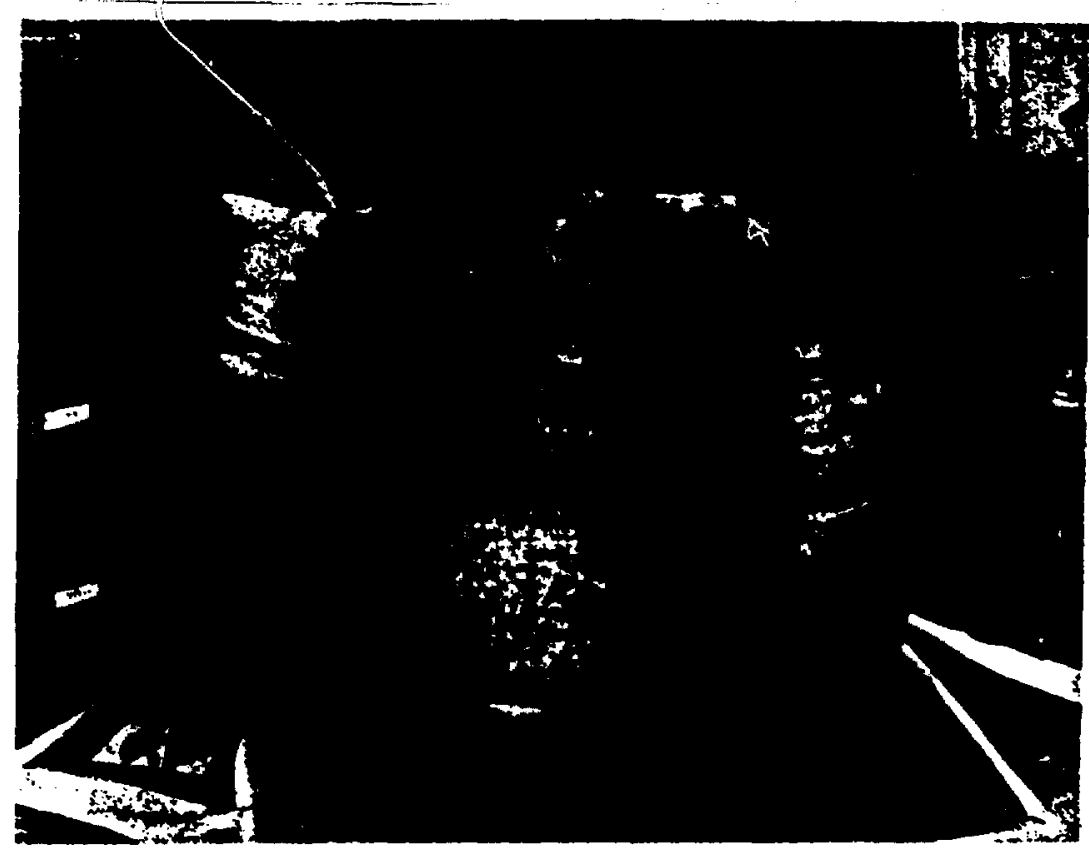

F18. 2. Photograph of Weldent 22BM. 
Before they were shipped to ANL, the weldments were sent to the J. A. Jones NDE Center in Charlotte, NC, where they were inspected by dye penetrant, ultrasonic, and radiographic techniques. Ultrasonic and radiographic techniques were difficult to apply to these weldments, but penetrant testing (PT) of the inner surface did reveal a limited amount of cracking in specimen 22BM. No crack indications were observed in specimen 22AM. These cracks were also detected by PT at ANL. Because of the limited amount of cracking in these weldments, the emphasis of the workshop was on trying to understand the nature of crack overcalling and the distortion of ultrasonic waves due to the presence of the overlay.

The statements below summarize some of the main conclusions drawn from workshop discussions.

- The ISI of piping with an overlay is unreliable for cracks that extend less than $\mathrm{N} 60 \%$ throughwall because of the unpredictable beam distortion due to the overlay (which can vary considerably in size and thickness from one weld to another) and the absence of effective reference pipes. Optimization of the inspection procedure will require documentation of the overlay procedure and the availability of reference mock-up pipes. These reference pipes should have reflectors in both the HAZ and the weld root. Field pipes removed from service are the most desirable.

- It is particularly difficult to separate crack signals from root signals when inspecting pipes with overlays because of the low signal-tonoise $(\mathrm{S} / \mathrm{N})$ ratio. It may be possible to improve the chance of detecting large cracks ( $\mathrm{J} 60 \%$ throughwa11) through use of longitudinal waves (Lwaves) and transducers with lower frequencies, although this will reduce the sensitivity to small cracks (less than $20 \%$ throughwa11).

- A baseline ultrasonic examination, performed with automated equipment, would be extremely useful as one could re-examine the pipe from time to time and look for changes resulting from crack initiation and growth. Automation makes this procedure feasible.

- The advantage of L-waves over shear waves for inspection of pipes with overlays is that L-waves undergo minimal attenuation and skewing while propagating through the overlay (or butt weld). It is also easier to see a crack tip signal with L-waves. The disadvantage is that the relative energy reflected back from a corner reflector is less than for shear waves.

- It may be easier to detect deep cracks that follow the fusion line by inspecting with L-waves through the weldment, because the crack face may then be nearly perpendicular to the beam. Overall, L-waves would be favored for pipes with an overlay.

A number of ultrasonic probes were used during this workshop. They included pitch-catch (side-by-side and tandem) and pulse-echo modes with both longitudinal and shear angle beams. Longitudinal beam angles of 45, 55 , and $70^{\circ}$, and shear beam angles of 45 and $60^{\circ}$, were used. A special probe that mode converts a shear wave into a surface-skimming bulk wave at the inner surface was also tried. Transducer frequencies ranged from 1 to $3 \mathrm{MHz}$ with sizes ranging from 6 to $25 \mathrm{~mm}$. USIP 11 , USL 48 , and Panametrics 5052 UAX pulser-receivers were employed during the laboratory investigation to allow analysis of both radio frequency and video signals. 
By means of the finger-damping technique, many ultrasonic echoes could be identifled as originating from the weld root. However, signals of unknown origin were detected at several transducer positions. These positions were carefully marked on the weldments. The amplitude of one signal of unknown origin using $2.25-\mathrm{MHz}$ shear waves, is about $8 \mathrm{~dB}$ lower in magnitude than a signal from a known IGSCC in a section of 28-in. pipe removed from service. This echo, as is the case for many others, has a favorable $S / N$ ratio and does not come from the weld root.

\section{ORIGIN OF SPURIOUS ECHOES}

The source of the above-mentioned spurious ultrasonic echoes detected during shear-wave examination of pipes with overlays appears to have been established and will be discussed below. The combination of a complex columnar grain structure and irregular boundary between overlay and base metal has been identified as the cause of echoes similar in appearance to those from cracks. This phenomenon has also been observed and discussed by other investigators [3]. Figure 3 shows a schematic of the pipe section, overlay, and transducer $(2.25 \mathrm{MHz}, 6 \mathrm{~mm})$ used to evaluate the problem. The pipe section (not from Hatch) has been ground flat and smooth on the inner and outer surfaces to leave a 5-mm-thick overlay and a combined thickness of $22.5 \mathrm{~mm}$. This eliminates any complications due to geometry.

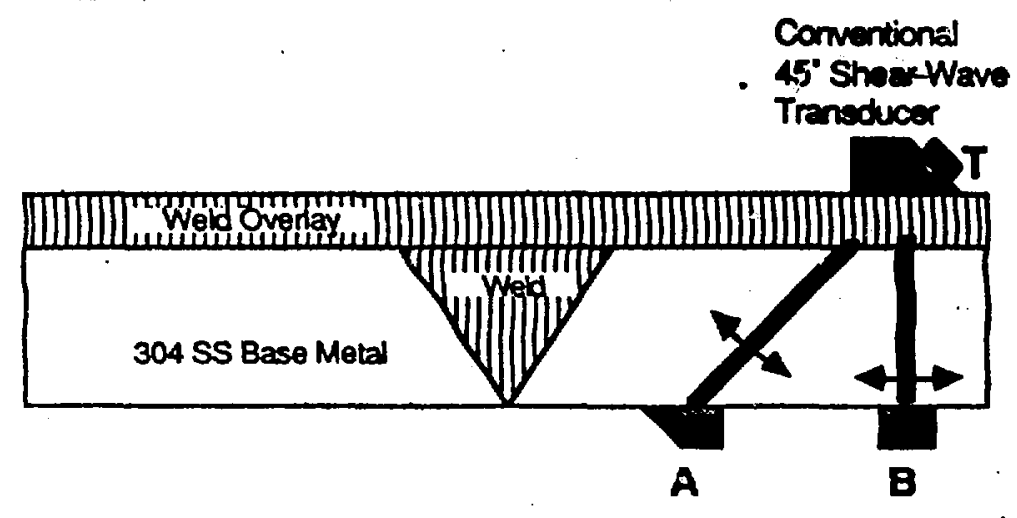

T: Conventional $45^{\circ}$ Shear-Wave Transducer Injects Ultrasonic Wave Into Overlay

A: Conventional $45^{\circ}$ Shear-Wave Transducer Detects SV-Wave in Through Transmission

B: Normal-Incidence Shear-Wave Transducer Below

Transmitting Transducer Detects Shear Wave with Polarization Parallel to Surface of Sample

Schematic of Pipe Section, Overlay, and Traneducers Used to Identify the Source of Spurfous Echoes Found During Ultrasonic Inspection of Pipes with Overlays. The total speciwen thickness is $22.5 \mathrm{~m}$. The overlay is $5 \mathrm{~mm}$ thick. A signal can be detected by $45^{\circ}$ shearwave transducer $A$ (at relative position indicated) for all locations of transmitter $T$. However, signals detected by normalincidence shear-wave transducer $B$ vary in amplitude depending on the position of $T$. A spurious echo is detected by $T$ (in pulse-echo mode) only when a relatively strong signal is detected by $B$. The difference in transit times for signals recelved at $A$ and $B$ for a given $T$ position is consistent with the difference in acoustic path length. 
complex microstructure of the overlay, the mode-converted shear wave is split into two parts [3]. One is an SV-wave propagating at N35-45 and the other is a wave propagating essentlally normal to the pipe surface. The SV-wave was detected by a conventional $45^{\circ}$ shear-wave transducer at the approximate position expected for a $45^{\circ}$ shear wave (corresponding to transducer A in Fig. 3 and trace 3 in Fig. 4). The other shear wave is reflected off the bottom of the pipe and returns to the transducer providing a strong ultrasonic echo (trace 2 in FIg. 5). An electromagnetic acoustic transducer (EMAT) and a normal-incidence shear-wave transducer were used to confirm the presence of this wave (transducer $B$ in Fig. 3 ). $A$ radially polarized EMAT was used to scan the inner surface of the sample. A shear wave was detected at a position just below or very slightly ahead of the $45^{\circ}$ shear-wave transducer wedge. A normal-incidence shear-wave transducer was used to establish that the polarization of this shear wave is parallel to the inner surface of the specimen and in the plane of the polarization of the conventional SV-wave (Fig. 4, trace 4). This wave cannot be detected by finger-damping techniques because there is no significant component of particle motion perpendicular to the surface. This also explains why the wave cannot be detected by conventional $45^{\circ}$ shear-wave transducers (transmission between two isotropic media across a fluid bouncary is not possible for shear waves with this polarization). When the normal-incidence shear-wave transducer $B$ shows a relatively large amplitude (Fig. 49, trace 4), a strong spurious signal is detected by the transmitting $45^{\circ}$ shear-wave transducer $T$ in the pulseecho mode (Fig.5, trace 2). When the normal-incldence shear-wave transducer $B$ shows a relatively weak signal amplitude there is no spurious echo.
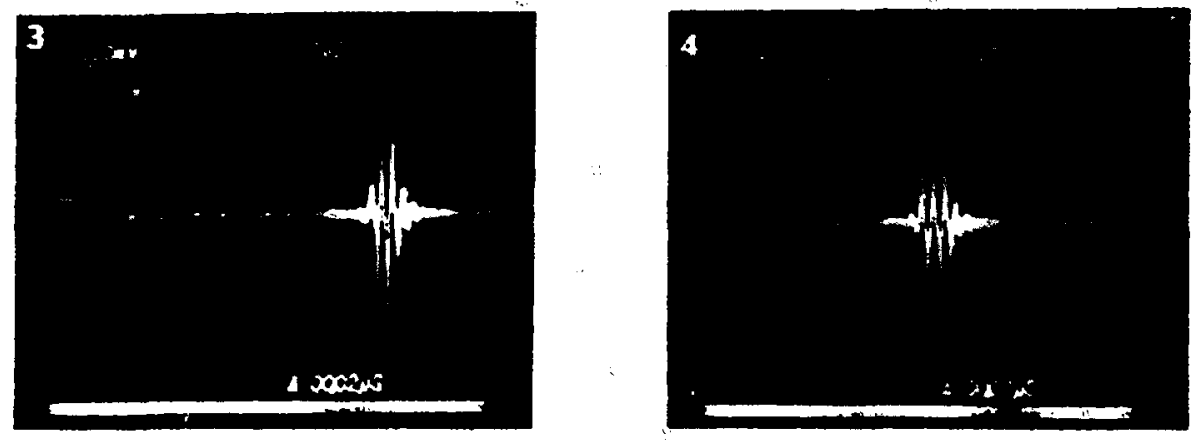

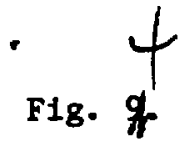

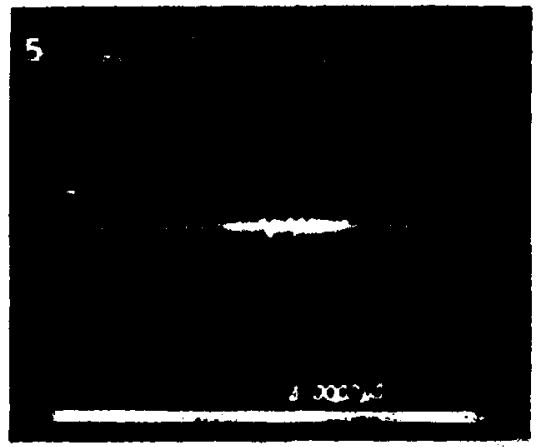

Signals Assoclated with a Given Position of $45^{\circ}$ Shear-Wave Transducer T (See F1g.34). Trace 3: signal recelved by $45^{\circ}$ shear-wave transducer at $A$. Trace $4:$ signal recelved by normal-incidence hear-wave transducer at $B$, with polarization as Indicated in Fig.3h. Trace 5: atgnal received by noralincidence shear-wave transducer at $B$, with polarization out of the plane of Fig.3 A. A Panawetrics 2.25-Miz, 13-man, normal-Incidence shear-wave transducer (B), KB-Aerotech

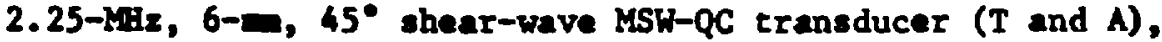


Is wroniricant couponent of particle motion perpendicular to the surface. This also explains why the wave cannot be detected by conventional $45^{\circ}$ shear-wave transducers (transmission between two isotropic media across a fluid boundary is not possible for shear waves with this polarization). When the normal-incidence shear-wave transducer $B$ shows a relatively large amplitude (Fig. 49, trace 4), a strong spurious signal is detected by the transmitting $45^{\circ}$ shear-wave transducer $T$ in the pulseecho mode (Fig.5, trace 2). When the normal-incidence shear-wave transducer $B$ shows a relatively weak signal amplitude there is no spurious echo.
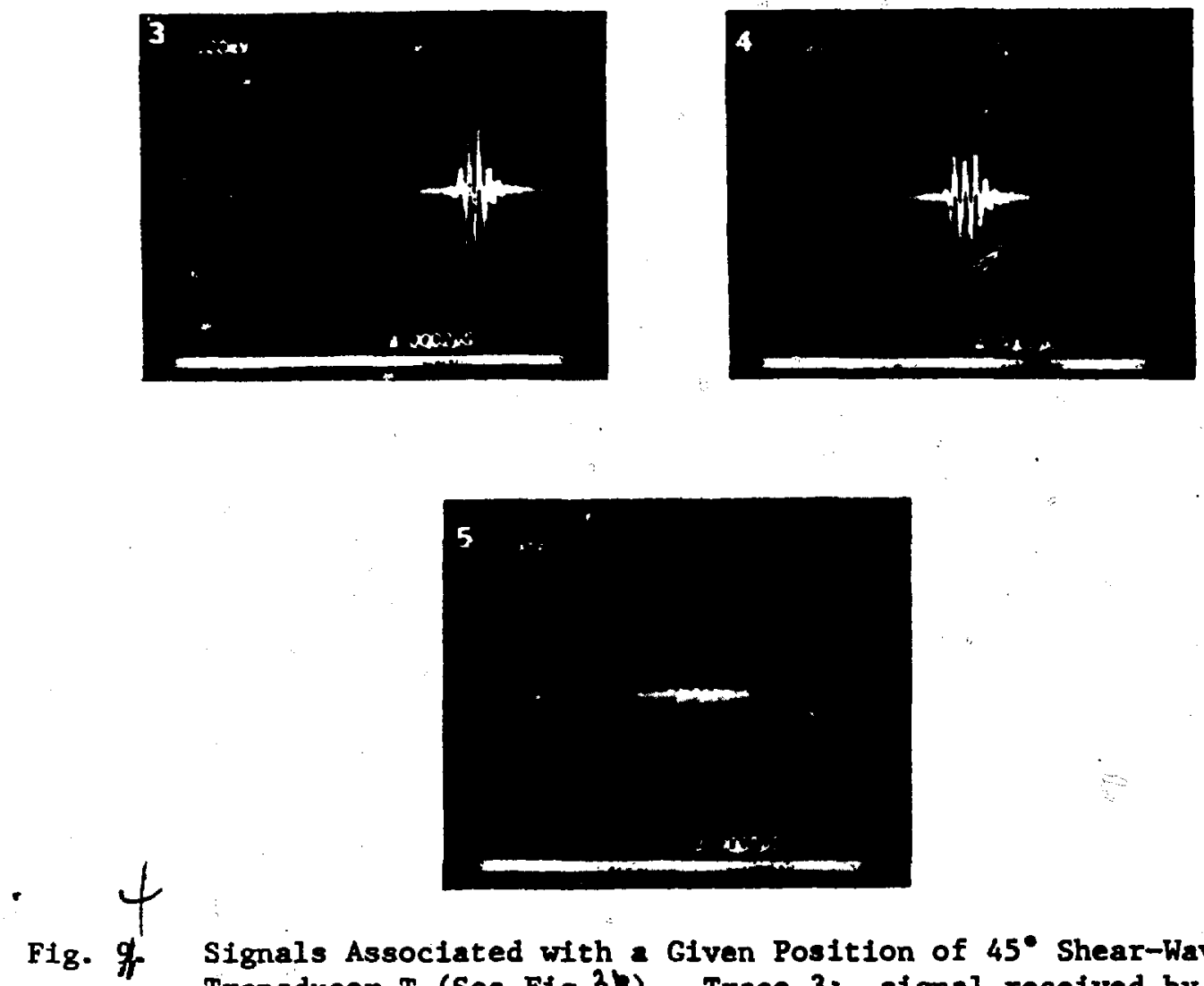

Signals Associated with a Given Position of $45^{\circ}$ Shear-Wave Transducer T (See Fig.3 ). Trace 3: signal received by $45^{\circ}$ shear-wave transducer at $A$. Trace 4: signal received by normal-incidence shear-wave transducer at $B$, with polarization as indicated in $\mathrm{Fig}_{\mathrm{g}} .3$. Trace 5: aignal received by noranincidence shear-wave transducer at $B$, with polarization out of the plane of $\mathrm{Fig}_{\mathrm{g}} 3 \mathrm{q}$. A Panametrics $2.25-\mathrm{MHz}, 13-\mathrm{mm}$, normal-incidence shear-wave transducer (B), RB-Aerotech 2.25-MHz, 6-m, 45 shear-wave MSW-QC transducer ( $T$ and $A$ ), and Pananerice 50520AX pulser-recelver were used in con-

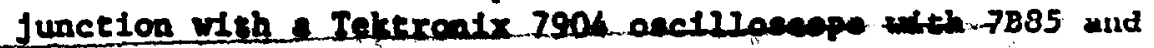
$7 B 80$ tim bases. 

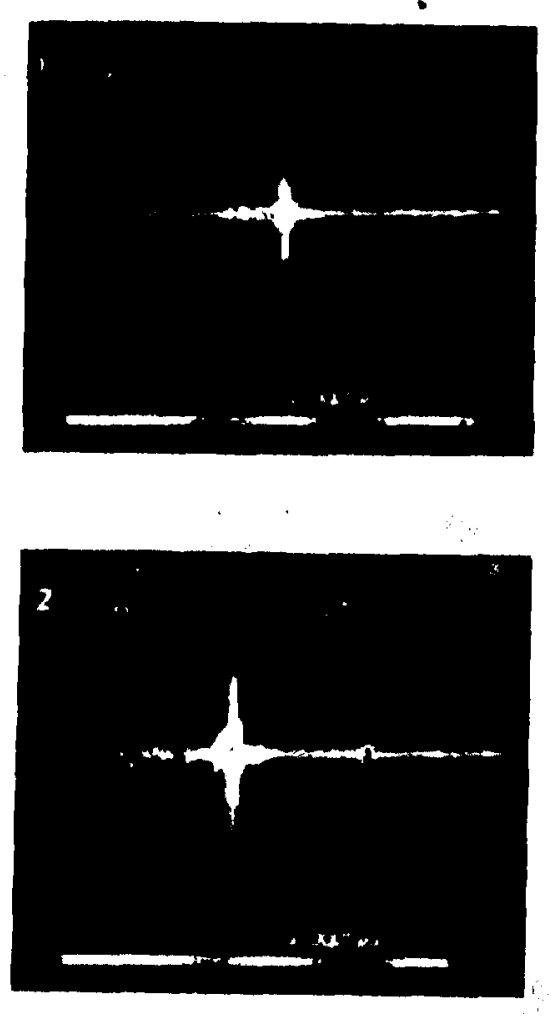

F18. Ip Trace 1: Radio-Frequency Signale fron Corner Reflector, Detected by Probe T after Propagating through the Overlay. Trace 2: Spurlous Echo Detected by Probe $T$ In the Pulea-Echo Mode (S1gnel Cannot be Finger Damed). Sam instrumantation a for Fig. 4.

The transit times for the spurious echo recelved at $T$ (Fig. 5, trace 2) and the echo received from a corner reflector (Fig. 5, trace 1) differ by $6 \mathrm{~ms}$. This corresponds to a path difference of about $18 \mathrm{~mm}$ ( $6 \mathrm{~ms} \times \mathrm{N} 3000 \mathrm{~m} / \mathrm{s}$ ). This acoustic path difference corresponds to the difference between a $45^{\circ}$ ohear wave and normal-incidence shear wave $\left[\left(22.5 \mathrm{~mm} / \cos 45^{\circ}-22.5\right) \times 2=18.6 \mathrm{mil}\right]$ and 80 is consistent with the explanations provided above.

When the $45^{\circ}$ shear-wave transducer is replaced by a $60^{\circ}$ transducer, the spurious pulse-echo signal is considerably reduced. In contrast, the through-transmitted signal detected by the normal-incidence shear-wave probe $B$ is large. Apparently, less of the reflected energy is transmitted to the wedge than for a $45^{\circ}$ probe. Furthermore, the spacing of the multiple echoes recelved at $B$, corresponds to the thickness of the specimen. Even more curlous is the observation that the relative amplitude of the first and second signal recelved at $B$ depends on the polarization of the recelving probe. If the polarization is as show in Fig. 3 , i.e., in the plane of the figure, the first olgnal is larger in amplitude than the second. If the polarization is rotated $90^{\circ}$, so as to be out of the plane of Fig. 3, the first signal is almost extinguished but the second malntains about the same amplitude.

One other relevant test has been carried out. A $60^{\circ}, 2.25-\mathrm{MHz}, 6-\mathrm{mm}$ shear-wave transducer was placed on a flat plece of $1-\mathrm{cm}-\mathrm{thick}$ SS weld metal at a location corresponding to $T$ in Fig. 3. The grain orientation in this specimen is generally the same as in the overlay of Fig. 3 , but does not follow the zig-zag pattern of the overlay (Fig. 6). The weld metal sample has a much more nearly ldeal transverse isotropic symmetry 


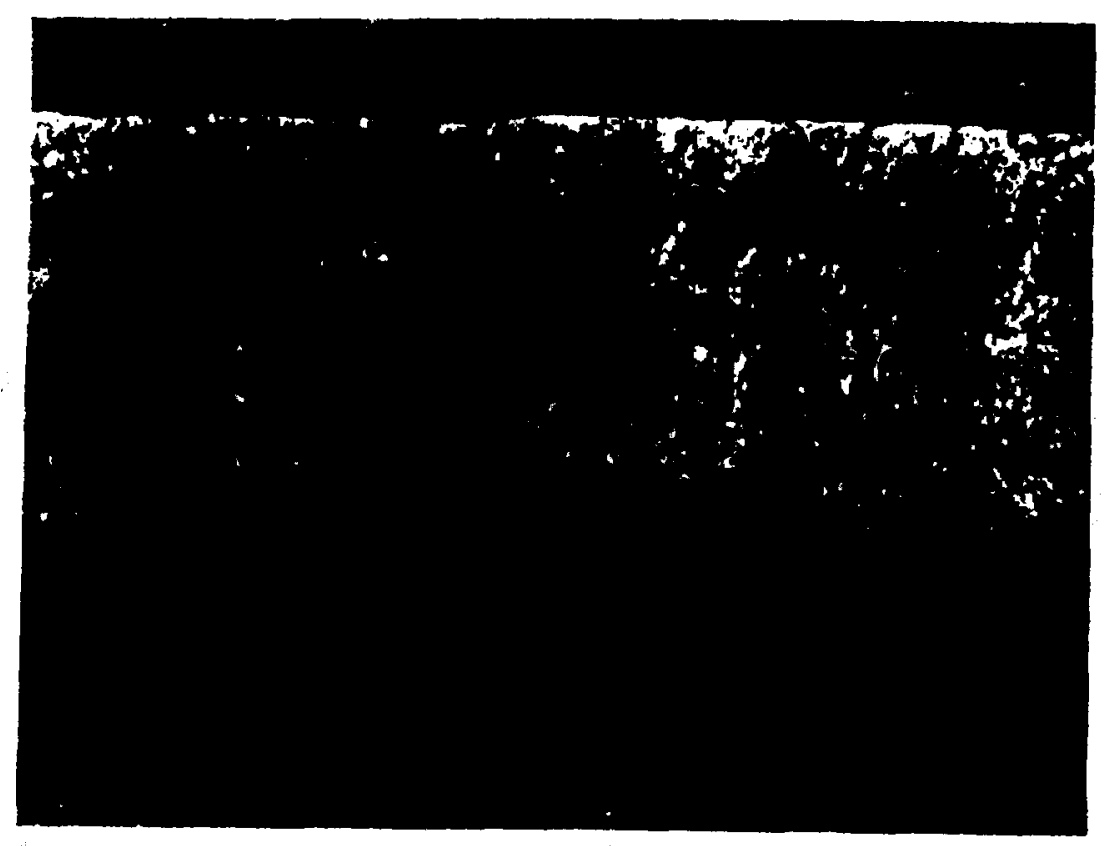

FI8. 话. Micrograph of Overlay from Hatch End-Cap, Showing Complex Grain Structure.

Than the overlay. No signals comparable to those found at B in Fig. 3 were found and no spurious echoes were detected. This suggests that it is the complex nature of the overlay, rather than simply the transverse isotropic symmetry, that causes the beam to split into two waves. The columnar grains in the overlay apparently result in the downward refraction of part of the injected beam.

We also compared $1-$ and $2.25-\mathrm{MHz}$ crystals with the same shear-wave, angle-beam wedge. The spurious echo amplitude detected by the $45^{\circ}$ shearwave transducer at $T$ was considerably less for the 1-MHz crystal, while the signals detected by the normal-incidence shear-wave transducer at $B$ were greater for the $1-\mathrm{MHz}$ crystal. This suggests that the ulcrasonic wavelength is an important parameter in the phenomenon and that the roughness of the overlay/base-metal interface and the size and orientation of the grains are important factors in the generation of the spurious echoes.

Despite the indications that longitudinal rather than shear-wave testing may be more reliable for pipes with overlays, shear-wave techniques are widely used in the fleld. As indicated, while scanning a weld overlay sample with shear waves, intermittent spurious or "phantom" echoes are generated. The data presented here supports the premise that these echoes are the result of part of the infected ultrasonic wave being refracted downward, reflecting of the inner wall of the pipe and returning to the transmitting probe. While it is difficult to see how this is possible, Fig. 7 illustrates a plausible path that results in a shear wave at almost normal incidence to the bottom surface. Close observation of the micrograph (Fig. 6) shows that this seemingly contrived arrangement of cokumnar grain structure is a strong possibility. By crossing boundaries that change the shear-wave velocity drastically, the shear wave can be refracted as indicated (see Ref. 4 for shear-wave velocity as a function of propagation direction in columnar structures.) Other arrangenents of columnar grain structures will result in part of the beam refracted in different directions but these will not be reflected back to the transmitting probe giving a false echo and possibly interpreted as originating at a crack. 


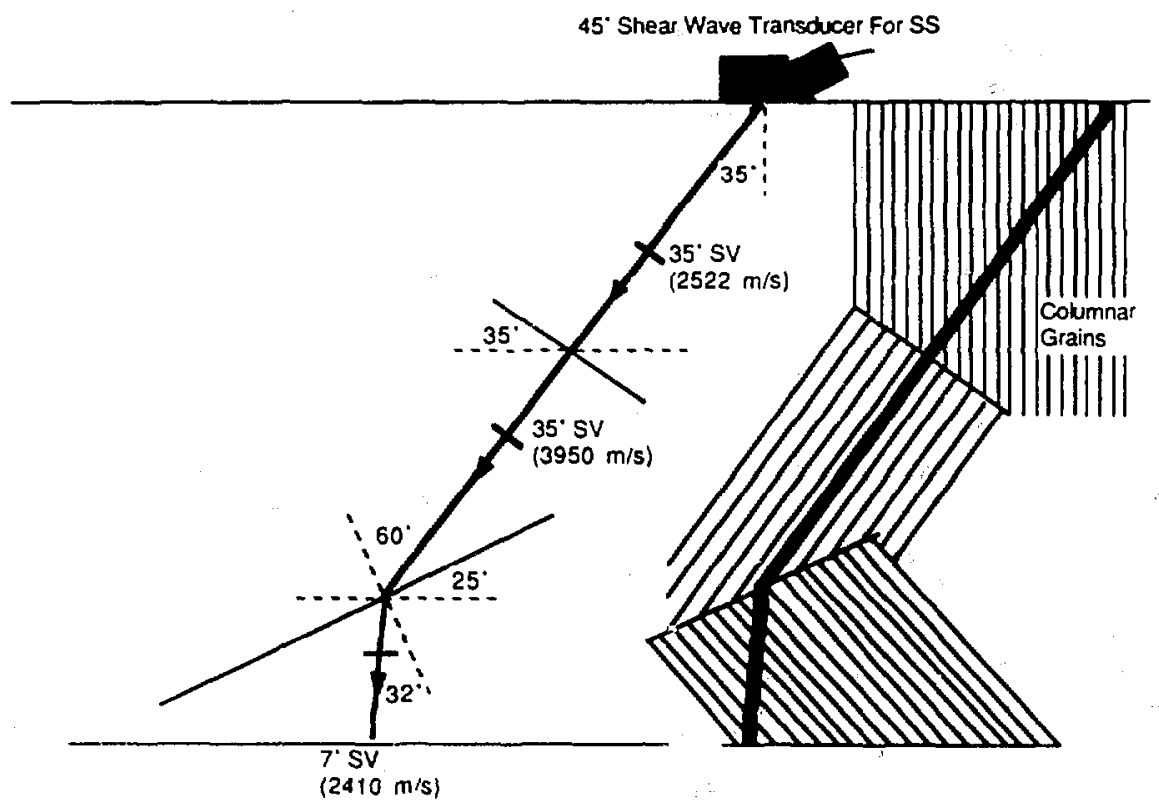

Fig. 7. Path of Shear Wavefront Normal in Weld Overlay.

\section{REFERENCES}

1. P. G. Heasler, D. J. Bates, T. T. Taylor, and S. R. Doctor, "Performance Demonstration Tests for Detection of Intergranular Stress Corrosion Cracking," Pacific Northwest Laboratory Report NUREG/CR-4464; PNL-5705, February 1986, p. 3.5.

2. D. S. Kupperman, T. N. Claytor, and D. W. Prine, "NDE of Stainless Steel and On-Line Leak Monitoring of LWRs: Annual Report October 1983-September 1984," Argonne National Laboratory Report NUREG/CR-4124, ANL-85-5, April 1985, p. 15.

3. H. Wustenberg, E. Schulz, and A. Erhard, Fundamental Influences on the Ultrasonic Inspection of Cladded Nuclear Components, Nucl. Eng. Des: 88(1):37-47. (August 1985).

4. D. S. Kupperman and K. J. Reimann, Ultrasonic Wave Propagation and Anisotropy in Austenitic Stainless Steel Weld Metal, IEEE Trans. Sonics and Ultrason. SU-27(1):7-15 (January 1980). 